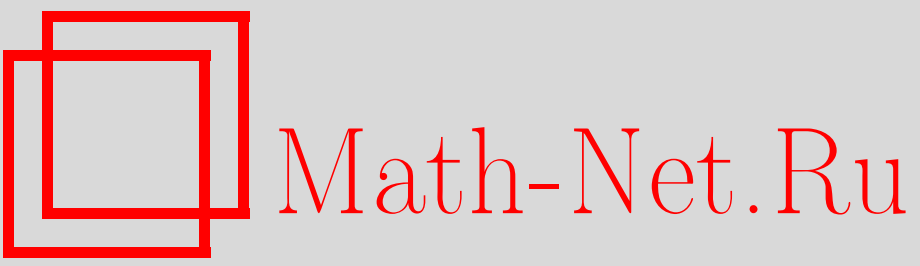

А. В. Арутюнов, Н. С. Бахвалов, М. Е. Боговский, В. С. Владимиров, А. А. Дезин, В. А. Ильин, Е. Ф. Мищенко, В. П. Маслов, С. М. Никольский, С. В. Успенский, В. М. Филиппов, Вера Николаевна Масленникова (некролог), УМH, 2001, том 56, выпуск 4, 129-132

DOI: https://doi.org/10.4213/rm418

Использование Общероссийского математического портала Math-Net.Ru подразумевает, что вы прочитали и согласны с пользовательским соглашением http://www. mathnet.ru/rus/agreement

Параметры загрузки:

IP : 3.95.254.165

26 апреля 2023 г., 02:35:48 


\section{ВЕРА НИКОЛАЕВНА МАСЛЕННИКОВА}

14 августа 2000 года скоропостижно скончалась доктор физико-математических наук, лауреат Государственной премии СССР, Заслуженный деятель науки Российской Федерации, профессор Масленникова Вера Николаевна.

В.Н. Масленникова родилась 29 апреля 1926 года в селе Прилуки под Вологдой. Уже в 11 лет лишившись родителей, она рано вступила в самостоятельную жизнь. В 1941 году Вера Николаевна поступила в Московский текстильный техникум. Осенью 1941 года вместе со студентами техникума участвовала в строительстве оборонительных укреплений под Москвой. Затем служила в 413-м отдельном зенитно-артиллерийском дивизионе в действующей армии. За участие в Великой Отечественной войне Вера Николаевна награждена орденом Отечественной войны и медалями.

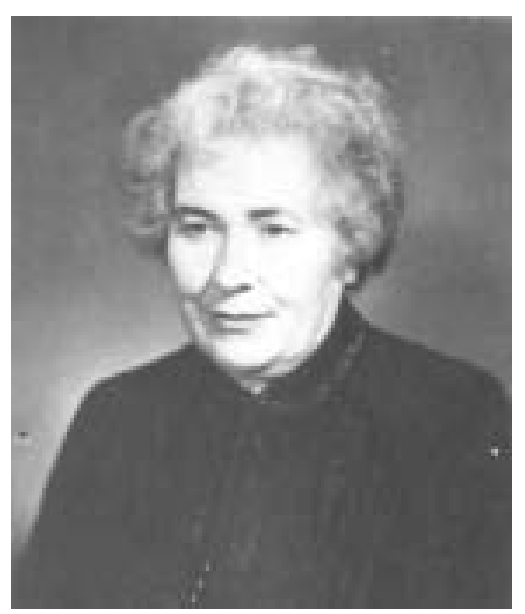

Осенью 1944 года Вера Николаевна возвращается к продолжению учебы, в 1946 году с золотой медалю заканчивает среднюю школу и поступает на механико-математический факултет Московского университета, который заканчивает с отличием в 1951 году.

Математические способности и любовь к математике у Веры Николаевны проявились еще в ранние школьные годы. Ее первым учителем в МГУ был А. О. Гельфонд, под руководством которого она защитила дипломную работу на тему "Построение решений в комплексной плоскости для одного дифференциально-разностного уравнения Урысона". После окончания МГУ Вера Николаевна поступила в аспирантуру Математического института им. В. А. Стеклова АН СССР к академику Сергею Львовичу Соболеву, и с этого времени в течение 40 лет ее научная деятельность была связана с именем этого великого математика.

После окончания аспирантуры в 1954 году Вера Николаевна в течение 22 лет работала в Математическом институте им. В. А. Стеклова, а с 1975 года и до конца жизни - в Российском университете дружбы народов (с 1975 по 1996 год заведовала там кафедрой диффференциальных уравнений и функционального анализа).

Верой Николаевной опубликовано 140 научных работ. Полученные ею резултаты в области дифференциальных уравнений в частных производных, математической гидродинамики и функциональных пространств пользуются широкой известностью и признанием в нашей стране и за рубежом.

Один из циклов работ относится к исследованию решений краевых задач для параболических уравнений. В этих работах установлен принцип максимума для параболических уравнений с разрывными коэффициентами, получены априорные оценки шаудеровского типа в классах Гёльдера для решений начально-краевых задач для параболического уравнения в областях, меняющихся со временем, при минимальных требованиях на исходные данные. 
Для многокомпонентных квазилинейных систем дифффузии ею изучены начально-краевые задачи, установлен принцип максимума в виде теорем сравнения, доказаны теоремы существования и единственности решений и даны приближенные методы отыскания этих решений.

Особенно большой цикл работ Веры Николаевны посвящен изучению поведения решений при неограниченном возрастании времени для различных линеаризованных систем гидродинамики вращающихся и стратифицированных жидкостей с учетом и без учета сжимаемости и вязкости. Ею получены точные по порядку убывания при $t \rightarrow \infty$ асимптотические оценки решения задачи Коши, равномерные по пространственным переменным, и осциллирующие асимптотические разложения по малому параметру $1 / t$ при различном числе пространственных переменных. Для вязкой вращающейся жидкости впервые был установлен интересньй факт: степень убьвания решения при $t \rightarrow \infty$ складывается из степени убьвания решения в случае вязкой жидкости без вращения и степени убывания решения без учета вязкости, но с учетом вращения. В.Н. Масленниковой и ее учениками доказано, что скорость стабилизации (к стационарному решению) в задаче Коши и началшно-краевых задачах и скорость выхода на пределную амплитуду в случае периодических внешних сил равны скорости убьвания решений при отсутствии источников. Были определены классы единственности для предельных амплитуд и изучены спектры операторов, порожденных краевыми задачами для линеаризованных систем гидродинамики вращающейся идеальной жидкости с учетом сжимаемости и с учетом сжимаемости и вязкости.

Вера Николаевна построила общую теорию задачи Коши и начально-краевых задач в анизотропных пространствах Соболева для различных систем гидродинамики вращающейся жидкости с переменными коэффициентами, в том числе и для вырожденных систем, в которых третье уравнение движения не содержит полной производной по времени. За цикл работ "Математические исследования по качественной теории вращающейся жидкости" Вере Николаевне совместно с группой ученых, возглавляемой С. Л. Соболевым, была присуждена Государственная премия СССР 1986 года.

Следующий цикл работ В. Н. Масленниковой, выполненньй совместно с ее учеником М. Е. Боговским, относится к построению $L_{p}$-теории аппроксимации соленоидальных и потенциальных векторных полей. Эти резултаты применяются к решению краевых и начально-краевых задач для эллиптических уравнений, систем Стокса и Навье-Стокса в неограниченных областях как с гладкими, так и с негладкими, в том числе некомпактными, границами.

С конца восьмидесятых годов В. Н. Масленникова вместе с М. Е. Боговским занималась решением начально-краевых задач, возникающих при математическом моделировании ураганов. Эти задачи сводятся к нелинейной нестационарной системе Навье-Стокса с краевыми условиями переменного порядка, при этом эволюция краевых условий может быть как гладкой, так и негладкой. Для изучения таких задач авторами был найден подход, позволивший оценить дробную гладкость решения по $t$ порядка $2 / 5$ вплоть до границы. Этот подход основан на регуляризации краевых условий с последующим пределным переходом по параметру регуляризации. Принципиальная новизна найденного подхода заключена в итерационной процедуре получения оценок гладкости, не зависящих от параметра регуляризации.

В цикле работ, выполненных вместе с М. Е. Боговским, по эллиптическим уравнениям второго порядка с переменными коэффициентами в плоских областях с компактными и некомпактными границами с угловыми особыми точками была построена полная теория задач Дирихле и Неймана во всей шкале пространств $L_{p}$ при $1<p<\infty$, т.е. найдены размерности ядра и коядра соответствующего эллиптического оператора, выяснено, когда область значений оператора не замкнута. Эти вопросы связаны с разложением $L_{p}$ в прямую сумму подпространств соленоидальных и потенциальных векторных полей. Для односвязной области $\Omega \subset \mathbb{R}^{2}$ с одной особой точкой был установлен критерий такой разложимости $L_{p}$. Формулируется этот критерий в терминах $\left(A_{p}\right)$-условия Макенхаупта на степень $\left|f^{\prime}(z)\right|^{2-p}$ модуля производной конформного отображения $f$ полуплоскости на область $\Omega$.

В. Н. Масленниковой и М. Е. Боговским был найден новьй подход к доказательству принципа максимума для нелинейного уравнения эволюционного типа. Вера Николаевна, совместно с ее учеником М. А. Тимошиным, построила $L_{p}$-теорию системы Стокса для задачи обтекания тел потоком вязкой несжимаемой жидкости в $\mathbb{R}^{3}$. В этих работах впервые построены явные реше- 
ния уравнений Стокса во внешности сферы в классах с полунормами $L_{p}^{1}$ и $L_{p}^{2}$, которые содержат как убьвающие и ограниченные, так и растущие при $|x| \rightarrow \infty$ решения. Для задачи обтекания конечного числа ограниченных тел в $\mathbb{R}^{3}$ была впервые правильно вычислена размерность ядра соответствующего оператора в классе $L_{p}^{2}$.

Вера Николаевна обладала болшшим педагогическим талантом и лекторским мастерством. Она автор прекрасного учебника по диффференциальным уравнениям в частных производных, имеющего гриф Минвуза России.

Много сил и времени Вера Николаевна отдавала подготовке молодых кадров. Работая в МИ$\mathrm{AH}$, она одновременно руководила дипломниками и аспирантами МФТИ. На кафедре диффференциальных уравнений и функционального анализа РУДН, которую Вера Николаевна возглавляла на протяжении более 20 лет, за это время было подготовлено более 400 специалистов с высшим образованием, более 60 кандидатов наук, как российских, так и иностранных. При этом сама Вера Николаевна была непосредственным научным руководителем более 40 дипломников и аспирантов из многих стран мира. Под ее непосредственным руководством подготовлено 16 кандидатов физико-математических наук. Первый аспирант Веры Николаевны защитил свою диссертацию в 1965 г. в Москве, а последний - в 2000 г. в Катманду, и знаменательно, что эта последняя защита стала историческим событием для Университета Катманду, явившись первой успешной защитой диссертации на соискание ученой степени Ph.D. в стенах самого молодого в Непале университета. Разнообразие направлений и тем курсовых, дипломных работ и диссертаций ее учеников, стремление учесть склонности и вкусы каждого наилучшим образом характеризует широту научных интересов Веры Николаевны. За болшие заслуги в деле подготовки студентов и аспирантов РУДН ей в 1996 году было присвоено звание Почетного профессора Российского университета дружбы народов.

Вера Николаевна была организатором и участником многих всесоюзных, российских и международных конференций. В течение 25 лет, начиная с 1964 года, она активно участвовала в советско-чехословацком сотрудничестве, являлась постоянным членом оргкомитета советско-чехословацких совещаний по проблеме "Методь функционального анализа и теории функций в задачах математической физики”. Под ее непосредственньм руководством было организовано десять советско-чехословацких совещаний по этой проблеме. Вера Николаевна была награждена золотой медалюю Бертрана Больцано Чехословацкой Академии наук за большой вклад в развитие теории дифференциальных уравнений в частных производных.

Вера Николаевна была очень энергичным, целеустремленным и требовательным человеком. При этом она оставалась обаятельной женщиной, душой любой компании, всегда отзывчивой и доброжелательной, готовой прийти на помощь в трудную минуту.

Имя Веры Николаевны навсегда сохранится в истории нашей науки, память о ней навсегда сохранится в сердщах всех, кто ее знал.

А. В. Арутюнов, Н. С. Бахвалов, М. Е. Боговский, В. С. Владимиров, А. А. Дезин, В. А. Ильин, Е. Ф. Мищенко, В. П. Маслов, С. М. Никольский, С. В. Успенский, В. М. Филиппов

\section{СПИСОК НАУЧНЫХ РАБОТ В. Н. МАСЛЕННИКОВОЙ}

[121] Hydrodynamical approach to modelling a dynamics of sea-waves generated by a hurricane // Int. Conference "Computational modelling and computing in Physics" (Dubna, September 1996). Abstracts. Dubna: Joint Inst. for Nuclear Research, 1996. P. 97 (with M.E. Bogovsky)

[122] О параболических уравнениях с условиями Дирихле на всей границе // УМН. 1996. Т. 51. № 5. С. 228-229 (совм. с М. Е. Боговским)

[123] Гидродинамический подход к моделированию динамики морских волн, создаваемых ураганом // Computational Modelling and Computing in Physics. Dubna: Joint Inst. for Nuclear Research, 1997. C. 352-359 (совм. с М. Е. Боговским)

Начало списка см. в журнале Вестник РУДН, сер. Математика. 1996. № 3, вып. 1. С. 7-14. 
[124] Дифференциальные уравнения в частных производных: Учебник. М.: Изд-во РУДН, 1997

[125] Generalized solution in the large for the Navier-Stokes system with a free surface separating two fluids // Int. Conference "Nonlinear partial differential equations" (Kiev, August 1997). Abstracts. Donetsk: Inst. Appl. Math. Mech., 1997. P. 126-127 (with M.E. Bogovsky)

[126] Решение стационарной задачи обтекания в постановке Стокса в пространствах $L_{p}^{2}(\Omega) / /$ Сиб. матем. журн. 1998. Т. 39. № 4. С. 908-930 (совм. с М. В. Кузнецовым)

[127] Система Навье-Стокса с негладкой эволюцией зависящего от времени разрьва в типе граничного условия // Докл. РАН. 1998. Т. 363. № 5. С. 594-598 (совм. с М.Е. Боговским)

[128] Задача обтекания в постановке Стокса в $L_{p}$-пространствах // УМН. 1998. Т. 53. № 4. C. 197

[129] Началнн-краевые задачи для нелинейной системы Навье-Стокса, моделирующие динамику урагана / / Третий Сибирский конгресс по прикладной и индустриальной математике, INPRIM-98, посвященный памяти С. Л. Соболева (Новосибирск, июнь 1998 г.). Тезисы докладов. Ч. І. Новосибирск: Изд-во Ин-та математики СО РАН, 1998. С. 25 (совм. с М. Е. Боговским)

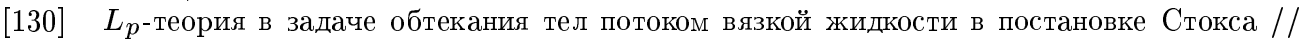
Межд. конф. "Функциональные пространства. Дифференциальные операторы. Проблемы математического образования", посвященная 75-летию проф. Л. Д. Кудрявцева (Москва, март 1998 г.). Тезисы докладов. М.: Изд-во РУДН, 1998. С. 141

[131] Generalized solution in the large for the Navier-Stokes system witha free surface separating two fluids // Nonlinear Boundary Value Problems. V. 8. Donetsk: Inst. Appl. Math. Mech., 1998. P. 179-192 (with M. E. Bogovsky)

[132] The Navier-Stokes equations with nonsmooth evolution of discontinuity in the type of boundary conditions // Int. Conference on Nonlinear Partial Differential Equations in Memory of S. N. Kruzhkov (Besançon, July 1999). Abstracts. Besançon, 1999. P. 34

[133] Navier-Stokes equations with unknown evolution of discontinuity in the type of boundary conditions // Nonlinear Partial Differential Equations. Internat. conference dedicated to J. P. Schauder (Lviv, August 1999). Book of Abstracts. Lviv: Lviv State Univ., 1999. P. 138 (with M.E. Bogovsky)

[134] Краевая задача для уравнения Пуассона для двух сред в $L_{p}^{2}$-пространствах // Матем. заметки. 1999. Т. 66. № 4. С. 515-526 (совм. с Ю. С. Верещагиной)

[135] О предельной амплитуде для решения системы Соболева в слое // XXXV Всероссийская конференция РУДН (Москва, март 1999 г.). Тезисы докладов. М.: Изд-во РУДН, 1999. С. 53-54 (совм. с М. В. Сорокиной)

[136] Краевая задача сопряжения для стационарной системы Стокса для двух сред в $L_{p}$-пространствах // XXXV Всероссийская конференция РУДН (Москва, март 1999 г.). Тезисы докладов. М.: Изд-во РУДН, 1999. С. 54-55 (совм. с Ю. С. Верещагиной)

[137] Краевая задача с условиями сопряжения двух сред для системы Стокса в $L_{p}^{2}$-пространствах // Четвертый Сибирский конгресс по прикладной и индустриальной математике, INPRIM-2000, посвященньй памяти М. А. Лаврентьева (Новосибирск, июнь 2000 г.). Тезисы докладов. Ч. І. Новосибирск: Изд-во Ин-та математики СО РАН, 2000. С. 16

[138] On asymptotics as $t \rightarrow \infty$ in initial-boundary value problems for systems in hydrodynamics of rotating fluid // Межд. конф. "Математическая физика, математическое моделирование и приближенные методы", посвященная памяти А. Н. Тихонова (Обнинск, май 2000). Тезисы докладов. Обнинск: Обнинский институт атомной энергетики, 2000. С. 40

[139] Asymptotics in hydrodynamics of rotating fluid with heat transfer // Вестник РУДН, сер. Математика. 2001. № 8 (совм. с Д. Б. Адхикари)

[140] Система Навье-Стокса с заданной негладкой эволюцией краевых условий переменного типа // Матем. сб. (в печати) (совм. с М.Е. Боговским) 